\title{
Trauma in Pregnancy : Diversifying Obstetric Retrieval Service in Sabah
}

C. Arrchana Chandrasegaran1, Phee-Kheng Cheah1, Arif Johari1 Muhamad Yaakub Ariffin1, Fatin Salwani Zaharuddin1 Emergency and Trauma Department ${ }^{1}$, Sabah Women and Children Hospital, Kota Kinabalu, Sabah, Malaysia

\section{ABSTRACT}

The Obstetric and Gynaecological Retrieval Service in West Coast Sabah has been well-established since year 2015, parallel to the global advancement of Emergency Retrieval Service. The decision to transfer a patient or to deploy team to the patient lies in the hands of Retrieval Unit. Additionally the mode of transportation, surgeon availability, weather and travel time have to be taken into account. Even though the structure of the program is steadfast in diversifying retrieval services, there are still insufficient studies available to decide it's worth. We report a case of a 19-year old primigravida at 27 weeks; involved in a high-impact motor vehicle accident and sustained class 4 hemorrhagic shock. Evaluated in a district hospital, uterine rupture was diagnosed. Hence, the dilemma was either to deploy a team to perform the surgery in district hospital, or to put the patient through a perilous joumey back. We would discuss on how we had organised and coordinated a team of obstetrician and anaesthesiologist, along with the Retrieval Team, to perform an Emergency Exploratory Laparotomy in district hospital. Nevertheless, the best method of care is still debatable as astute judgement is crucial and this approach has to be taken on a case to case basis. Ultimately, the patient's well-being is the utmost priority.

\section{INTRODUCTION}

Trauma continues to be the leading non obstetrical cause of maternal death.(1) It happens in $5 \%$ to $7 \%$ of all pregnancies. $(2,3)$

- In West Coast Sabah, Sabah Women and Children Hospital (SWACH) is the one and only tertiary hospital that function as satellite to provide acute obstetric services. Activation of O\&G retrieval was integrated into the PHC system in SWACH since August 2015 (4)

- This retrieval service is a joint effort between pre hospital care team and $O \& G$ team due to limitations in district hospital.

Statistically, we respond to $x x x(\%)$ of post party hemorrhage and, $x x x x(\%)$ eclampsia cases, etc

This is our maiden trauma in pregnancy retrieval case that cast a challenge for us. Therefore, we elaborate the challenges and reasoning behind every decision.
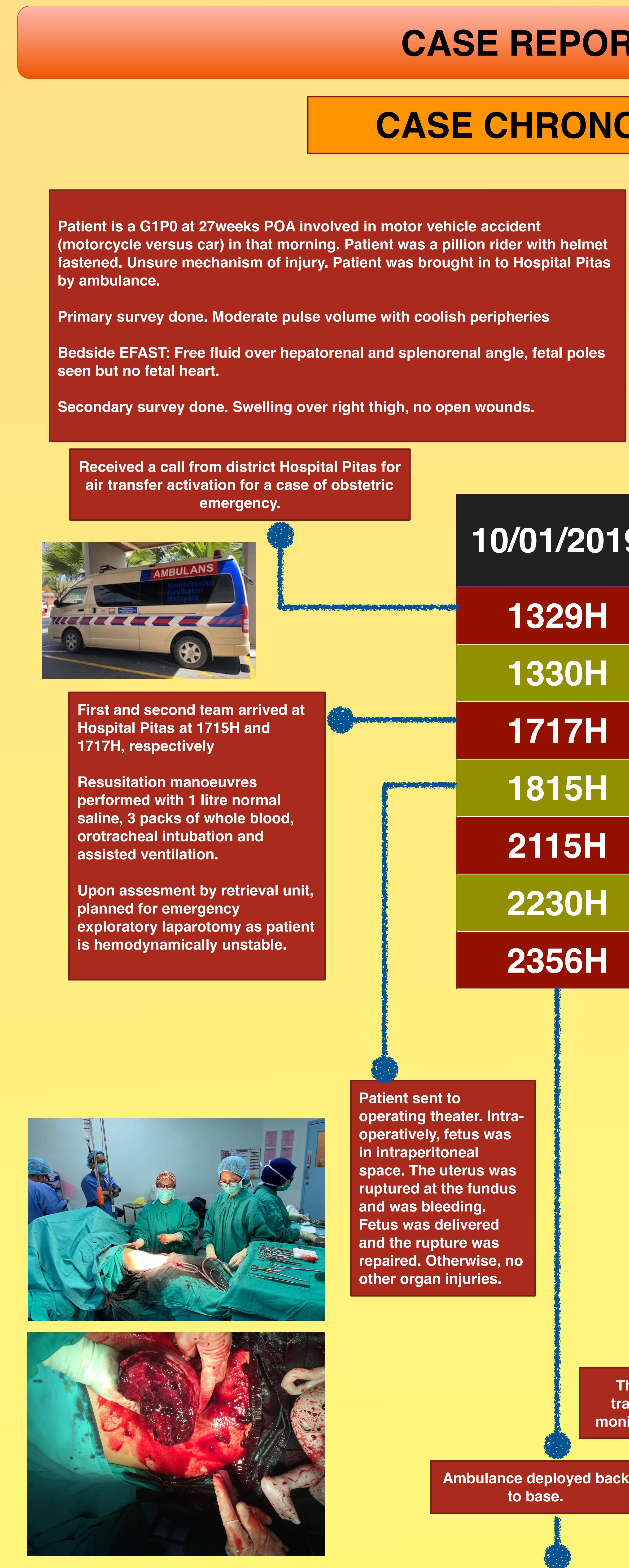

$1329 \mathrm{H}$

$1330 \mathrm{H}$

$1717 \mathrm{H}$

2115H

$2230 \mathrm{H}$
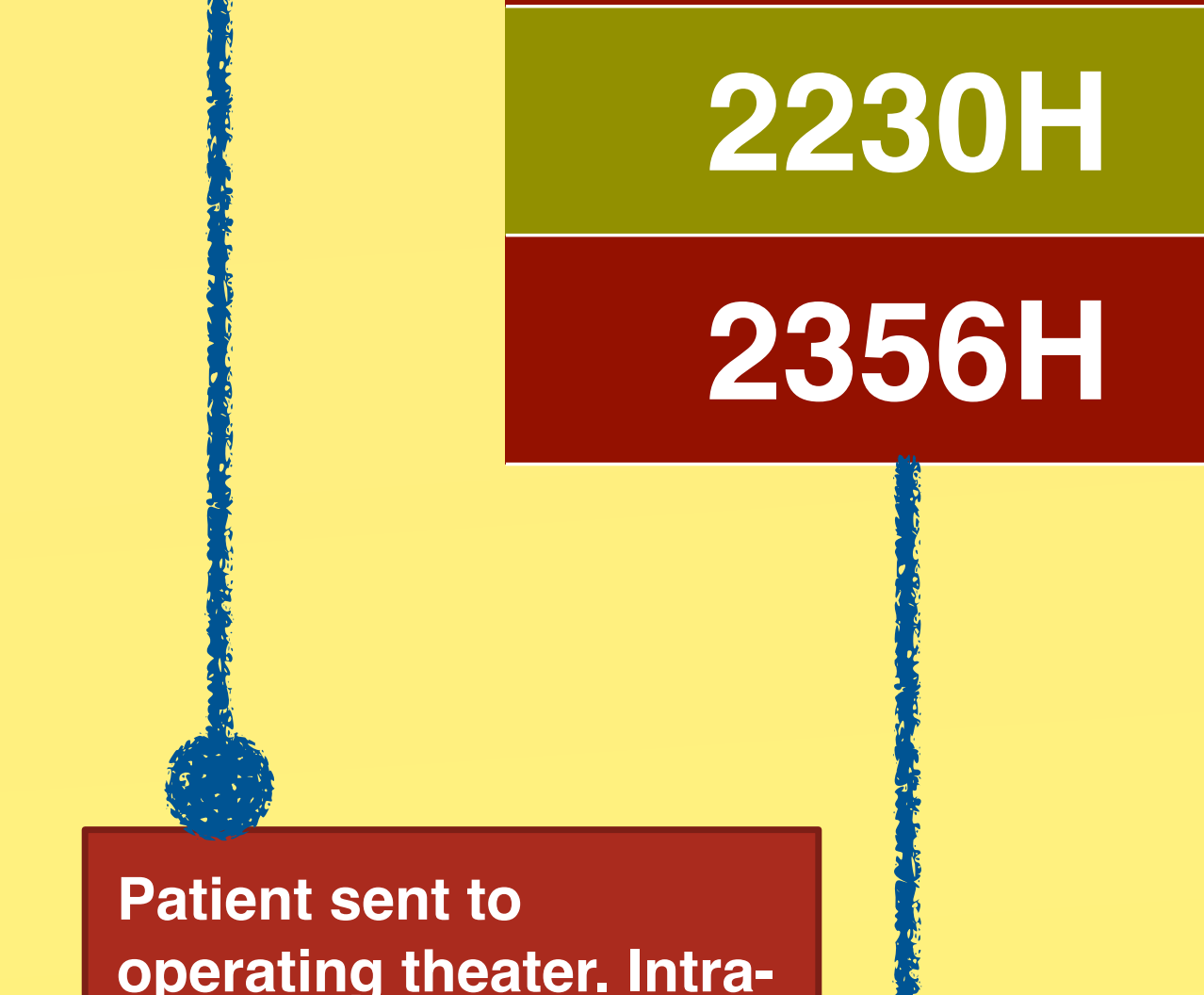

\section{CASE CHRONOLOGY}

\section{Pitas for}

\section{$10 / 01 / 2019$}
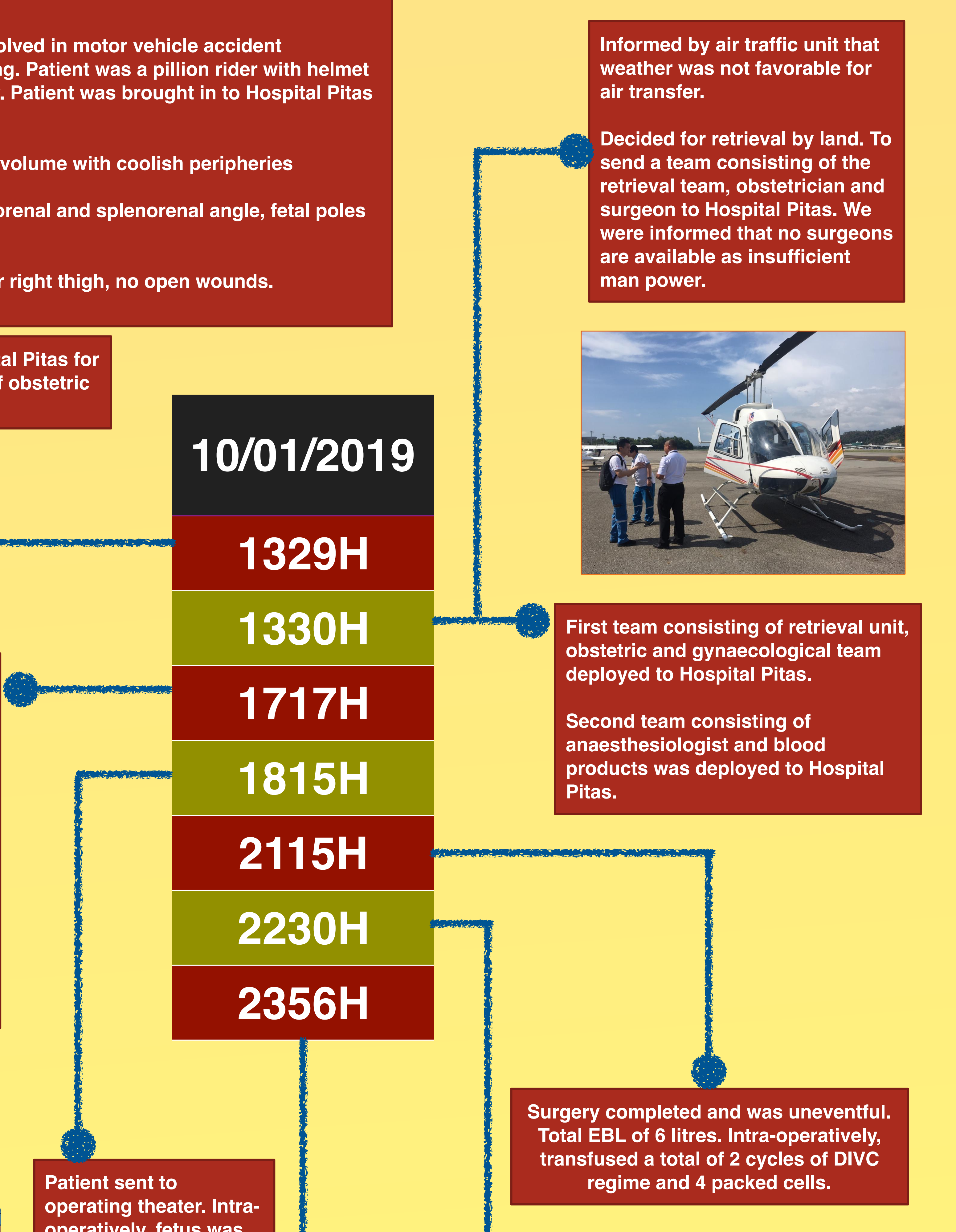

\section{(1)}

\section{DISCUSSION}

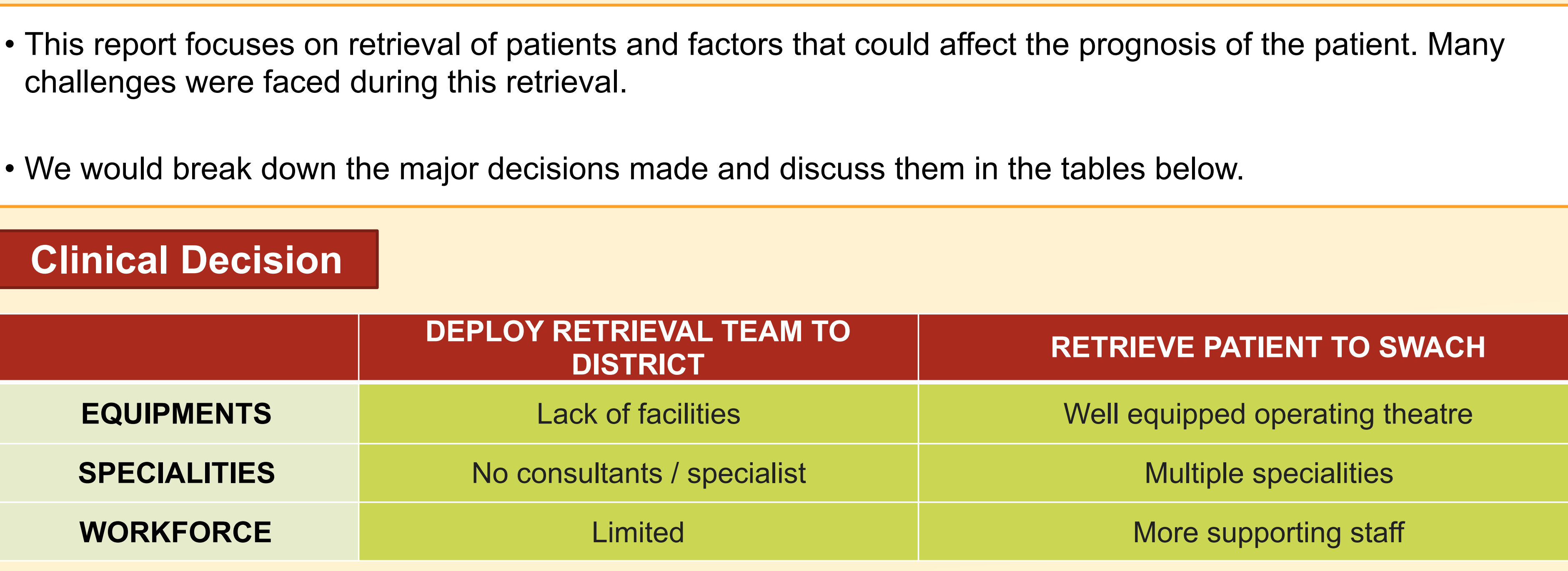

Conclusion : Even though the best course of action is to retrieve the patient back to SWACH, she is hemodynamically unstable. Transferring her without surgical intervention would increase the risk of further deterioration during the transfer. Therefore, at that point deploying a team to Hospital Pitas seemed to be the better option.

\begin{tabular}{|c|c|c|c|}
\hline \multicolumn{2}{|c|}{ AIR TRANSPORT } & \multicolumn{2}{|c|}{ LAND TRANSPORT } \\
\hline \multirow{5}{*}{\begin{tabular}{l}
\multicolumn{1}{c}{ Pros } \\
Reduces out-of-hospital \\
transport time \\
Suitable for long distance \\
Greater manoeuvrability
\end{tabular}} & Cons & Pros & Cons \\
\hline & $\begin{array}{l}\text { Inability to fly during extreme } \\
\text { weather conditions }\end{array}$ & \multirow{4}{*}{$\begin{array}{l}\text { Rapid mobilization } \\
\text { Door-to-door transport } \\
\text { Less dependant of weather }\end{array}$} & \multirow{4}{*}{$\begin{array}{l}\text { Traffic and road condition } \\
\text { might delay the transfer } \\
\text { Slower on long distance }\end{array}$} \\
\hline & The need for a dedicated & & \\
\hline & $\begin{array}{l}\text { Requires highly trained } \\
\text { nersonnels }\end{array}$ & & \\
\hline & $\begin{array}{l}\text { Changes in air pressure may } \\
\text { affect patient's condition and } \\
\text { medical equipments }\end{array}$ & & \\
\hline
\end{tabular}

Conclusion : In this case, aeromedical transfer is the better option as time is crucial and the distance to the hospital. However it not feasible due to the weather condition. (5) Therefore, the only available mode of transportation is through land transfer.

\section{Challenges}

\begin{tabular}{|c|c|}
\hline PROBLEM & SOLUTION \\
\hline No specialist available to assess severity of patient & A O\&G specialist deployed along with ERU team \\
\hline No anaesthesiologist available in district & A senior anaesthesiologist deployed from SWACH \\
\hline Lack of blood products & Blood products from SWACH was brought along \\
\hline Insufficient surgical equipments in Hospital Pitas & Hysterectomy set was brought along \\
\hline
\end{tabular}
Table 3 : Challenges faced and the solutions

- Every possible issue that might arise was anticipated prior to deploying the retrieval unit. Decisions were made according to availability of facilities and staffs.

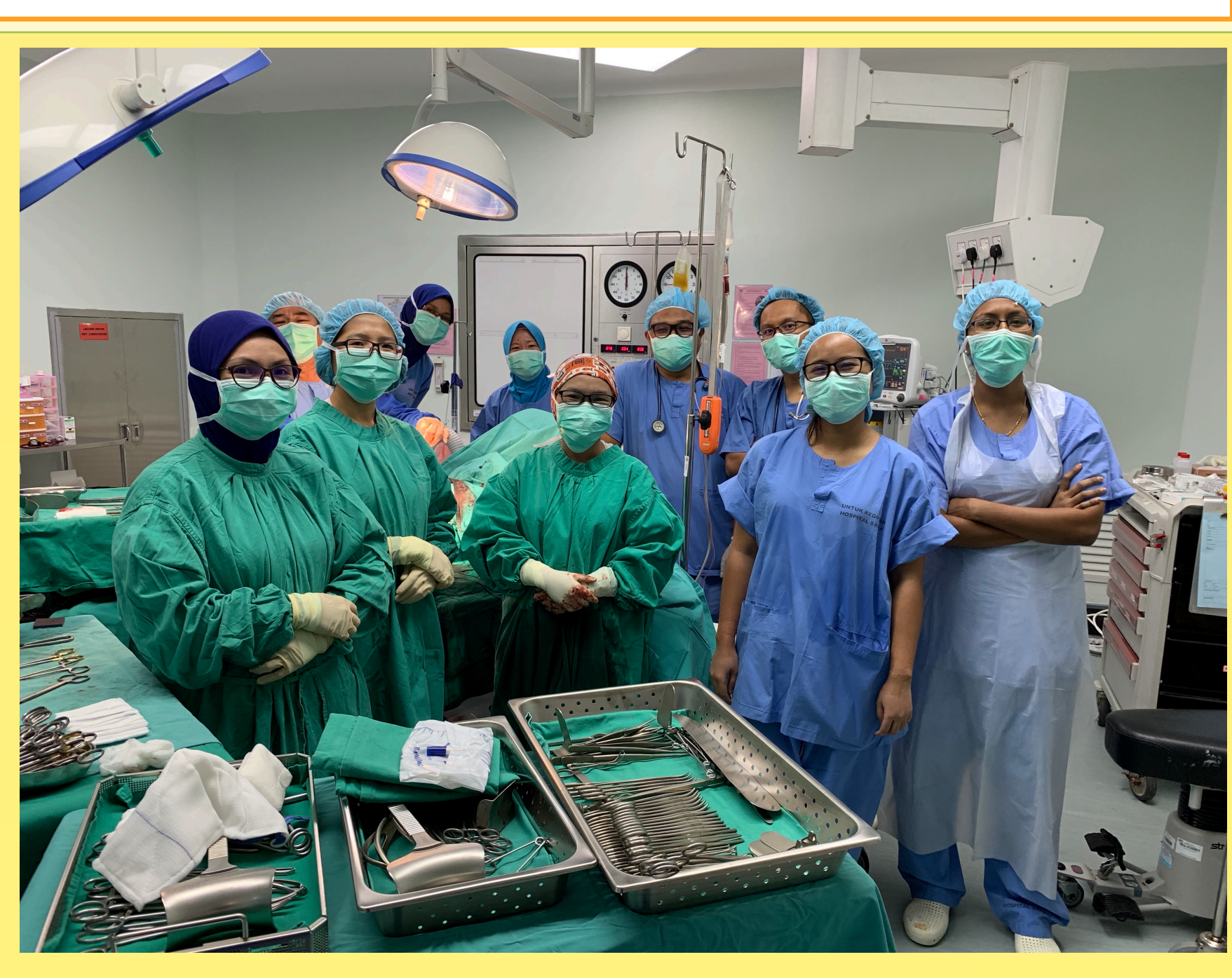

\section{CONCLUSION}

A number of thought process will have to occur simultaneously prior to retrieval of patient. Every case is different and has to be evaluated independently, prior to making the decision whether to deploy a team to the scene or to retrieve the patient as there is no one-thumb rule.

\section{REFERENCE}

[1] Weinber L, Steele RG, Pugh R, Higgins S, Herbert M, Story D. The pregnant trauma patient. Anaesth Intensive Care 2005;33:167-80 [2] Hill CC, Pickinpaugh J. Trauma and surgical emergencies in the obstetric patient. Surg Clin North Am 2008;88:421- 40. [3] Green W, Robinson L, Rizzo AG, et al. Pregnancy is not a sufficient indicator for trauma team activation. J Trauma 2007:63:550 -5. [4] Nurul Liyana Idrus, Phee-Kheng Cheah, Muhammad Yaakub Arifin, Ruey Soon, Implementation of O\&G Retrieval System in Kota

[5] Moga, Carmen \& Harstall, Christa. (2008). Air ambulance transportation with capabilities to provide advanced life support. 